\title{
Increased flood risk linked to global warming
}

\section{Likelihood of extreme rainfall may have been doubled by rising greenhouse-gas levels.}

\section{BY QUIRIN SCHIERMEIER}

$\mathrm{C}$ limate change may be hitting home. Rises in global average temperature are remote from most people's experience, but two studies in this week's Nature ${ }^{1,2}$ conclude that climate warming is already

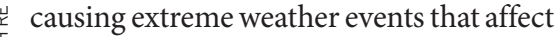
the lives of millions. The research directly links rising greenhouse-gas levels with the growing intensity of rain and snow in the Northern Hemisphere, and the increased risk of flooding in the United Kingdom.

Insurers will take note, as will those developing policies for adapting to climate change. "This has immense importance not just as a further justification for emissions reduction, but also for adaptation planning," says Michael Oppenheimer, a climate-policy researcher at Princeton University in New Jersey, who was not involved in the studies.

There is no doubt that humans are altering the climate, but the implications for regional weather are less clear. No computer simulation can conclusively attribute a given snowstorm or flood to global warming. But with a combination of climate models, weather observations and a good dose of probability theory, scientists may be able to determine how climate warming changes the odds. An earlier study $^{3}$, for example, found that global warming has at least doubled the likelihood of extreme events such as the 2003 European heatwave.

More-localized weather extremes have been harder to attribute to climate change until now.

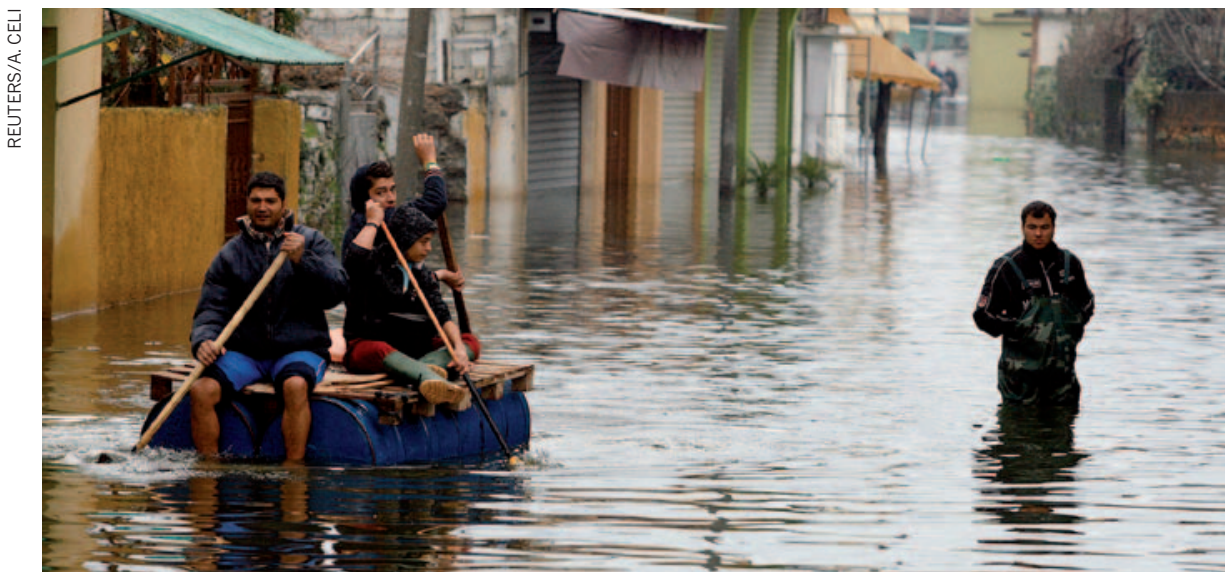

The effects of severe weather — such as these floods in Albania — take a huge human and financial toll.

"Climate models have improved a lot since ten years ago, when we basically couldn't say anything about rainfall," says Gabriele Hegerl, a climate researcher at the University of Edinburgh, UK. In the first of the latest studies ${ }^{1}$, Hegerl and her colleagues compared data from

\section{FATAL FLOODS}

The most severe floods of the past 30 years cost thousands of lives and caused billions of dollars of damage.

\begin{tabular}{l|l|l|l} 
Period & Region & $\begin{array}{l}\text { Overall losses } \\
\text { (US\$ billion) }\end{array}$ & Deaths \\
May-Sept. 1998 & China & 30.7 & 4,150 \\
June-Aug. 1996 & China & 24 & 3,050 \\
June-Aug. 1993 & United States & 21 & 50 \\
Aug. 2002 & Europe & 16.5 & 40 \\
July-Aug. 1995 & North Korea & 15 & 70
\end{tabular}

weather stations in the Northern Hemisphere with precipitation simulations from eight climate models (see page 378 ). "We can now say with some confidence that the increased rainfall intensity in the latter half of the twentieth century cannot be explained by our estimates of internal climate variability," she says.

The second study ${ }^{2}$ links climate change to a specific event: damaging floods in 2000 in England and Wales. By running thousands of high-resolution seasonal forecast simulations with or without the effect of greenhouse gases, Myles Allen of the University of Oxford, UK, and his colleagues found that anthropogenic climate change may have almost doubled the risk of the extremely wet weather that caused the floods (see page 382). The rise in extreme precipitation in some Northern Hemisphere areas has been recognized for more than a decade, but this is the first time that the anthropogenic contribution has been nailed down, says Oppenheimer. The findings mean that Northern Hemisphere countries need to prepare for more of these events in the future. "What has been considered a 1-in100 -years event in a stationary climate may actually occur twice as often in the future," says Allen.

But he cautions that climate change may not always raise the risk of weather-related damage. In Britain, for example, snowmelt floods may become less likely as the climate warms. And Allen's study leaves a $10 \%$ chance that global warming has not affected - or has even decreased - the country's flood risk.

Similar attribution studies are under way for flood and drought risk in Europe, meltwater availability in the western United States and drought in southern Africa, typical of the research needed to develop effective climateadaptation policies. "Governments plan to spend some US $\$ 100$ billion on climate adaptation by 2020, although presently no one has an idea of what is an impact of climate change and what is just bad weather," says Allen.

Establishing the links between climate change and weather could also shape climate treaties, he says. "If rich countries are to financially compensate the losers of climate change, as some poorer countries would expect, you'd like to have an objective scientific basis for it."

The insurance industry has long worried about increased losses resulting from more extreme weather (see 'Fatal floods'), but conclusively pinning the blame on climate change will take more research, says Robert Muir-Wood, chief research officer with RMS, a company headquartered in Newark, California, that constructs risk models for the insurance industry. "This is a key part of our research agenda and insurance companies do accept the premise" that there could be a link, he says. "If there's evidence that risk is changing, then this is something we need to incorporate in our models." - SEE NEWS AND VIEWS P.344

1. Min, S.-K. et al. Nature 470, 378-381 (2011)

2. Pall, P. et al. Nature 470, 382-385 (2011).

3. Stott, P. A. et al. Nature 432, 610-614 (2004). 